\title{
Cutting forces during longitudinal turning process of TI-6AL-4V ELI alloy. Theoretical and experimental values
}

Wojciech STACHURSKI

DOI: 10.30464/jmee.2018.2.3.201

Cite this article as:

Stachurski W. Cutting forces during longitudinal turning process of TI-6AL-4V ELI alloy. Theoretical and experimental values. Journal of Mechanical and Energy Engineering, Vol. 2(42), No. 3, 2018, pp. 201-206.

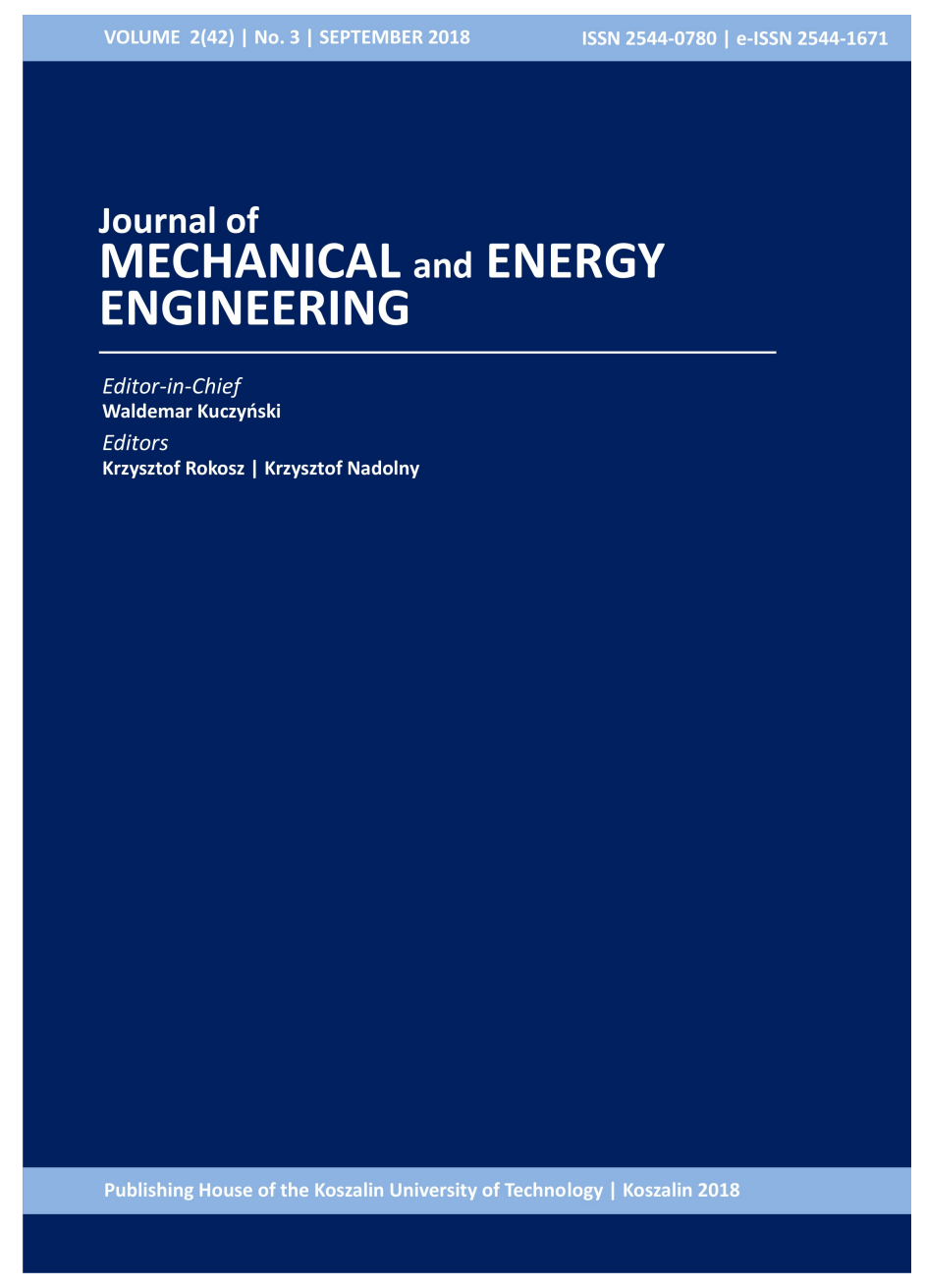

Journal of Mechanical and Energy Engineering

Website: jmee.tu.koszalin.pl

ISSN (Print): 2544-0780

ISSN (Online): 2544-1671

Volume: 2(42)

Number: 3

Year: 2018

Pages: 201-206

Article Info:

Received 14 July 2018

Accepted 3 September 2018

\section{Open Access}

This article is distributed under the terms of the Creative Commons Attribution 4.0 (CC BY 4.0) International License (http://creativecommons.org/licenses/by/4.0/), which permits unrestricted use, distribution, and reproduction in any medium, provided you give appropriate credit to the original author(s) and the source, provide a link to the Creative Commons license, and indicate if changes were made. 


\title{
CUTTING FORCES DURING LONGITUDINAL TURNING PROCESS OF TI-6AL-4V ELI ALLOY. THEORETICAL AND EXPERIMENTAL VALUES
}

\author{
Wojciech STACHURSKI ${ }^{1 *}$ \\ ${ }^{1 *}$ Institute of Machine Tools and Production Engineering, Lodz University of Technology, \\ Stefanowskiego 1/15, 90-924, Lodz, Poland, e-mail: wojciech.stachurski@p.lodz.pl
}

(Received 14 July 2018, Accepted 3 September 2018)

\begin{abstract}
In the paper, the experimental investigations related with longitudinal turning of Ti-6Al-4V ELI alloy (Grade 23) typically used in aeronautics industry have been presented. The main goal was to determinate the influence of changes in a selected cutting parameters $\left(v_{c}\right.$ and $f$ ) for total cutting force $F_{c}$ and its components. In this case, the analysis of the components of cutting force $F_{c}$ measured during workshop experimental investigations was carried out. Next, the measured values were compared with the values calculated on the basis of formulas available in the literature. This allowed one to state that universal theoretical formulas can also be used to determine the components of the total cutting force $F$ in the longitudinal turning process of Ti-6Al-4V ELI alloy.
\end{abstract}

Keywords: Titanium alloys, turning, cutting force

\section{INTRODUCTION}

Machining is the most commonly used technology for the shaping of construction materials, including hard-to-cut materials. This material group includes titanium and titanium alloys, used mainly in the aerospace, medical, automotive, marine and chemical industries [1-5]. This area of application results from the properties which these materials are characterized by. These are: very high corrosion resistance, a high value of strength-to-density ratio, high temperature resistance, high strength under long-term load conditions and biocompatibility [6-10].

A big difficulty in the wide use of titanium alloys is presented by problems in their machining. These problems are related to the occurrence of high cutting temperatures and rapid wear of cutting tools. Available studies from this area [2, 3, 4, 6, 11] indicate the main reasons for these problems, including: a low thermal conductivity coefficient, high chemical reactivity with the majority of tool materials, thermoplastic instability during machining, a tendency of chips sticking to the tool, or finally a tendency to create a built-up edge (BUE), which favors the wear of cutting blade. An improvement in the machinability of titanium alloys can be achieved by lowering the cutting temperature. Recommendations for machining titanium alloys indicate the necessity of cutting with a low cutting speed, high feed and depth of cut (in comparison to steel processing) using very sharp tools [6]. For blades made of sintered carbides, is recommended to use a cutting speed of less than 60 $\mathrm{m} / \mathrm{min}$ at feeds in the range of $0.2-0.5 \mathrm{~mm} / \mathrm{rev}$ [3]. Another recommendation, to decrease the unfavorably high cutting temperature, is the use of abundant delivering of the cutting fluid. The delivering of machining liquid with a large expense is to extend the tool life by increasing the amount of heat taken over and reducing the cutting forces and improving the removal of chips from the machining zone [3, 12].

One of the evaluation methods of the cutting process is based on an analysis of the total cutting force $F$ (crea-ted during machining) and its components. Their values indicate the loading degree of the cutting blade, and thus give an overview of the cutting conditions and the possibility of predicting the tool life period. The values of cutting forces can be determined by means of an experiment and analytical methods.

The main goal of this work is determinate the influence of changes in selected cutting parameters for 
values of total cutting force and its components during longitudinal turning process of Ti-6Al-4V ELI alloy (Grade 23). In this case, the Author proposes to carry out an analysis of the components of cutting force $F_{c}$ and compare the measured values with the values calculated on the basis of formulas available in the literature. This allowed the Author to state that universal theoretical formulas can also be used to determine the components of the total cutting force $F$ in the longitudinal turning process of Ti-6Al-4V ELI.

\section{CUTTING FORCE IN TURNING}

The total cutting force $\mathrm{F}$ is the force that affects the workpiece, separates the material and converts it into a chip. The force $\mathrm{F}$ can be divided into three directions of the Cartesian coordinate system $x, y, z$ (Fig. 1).

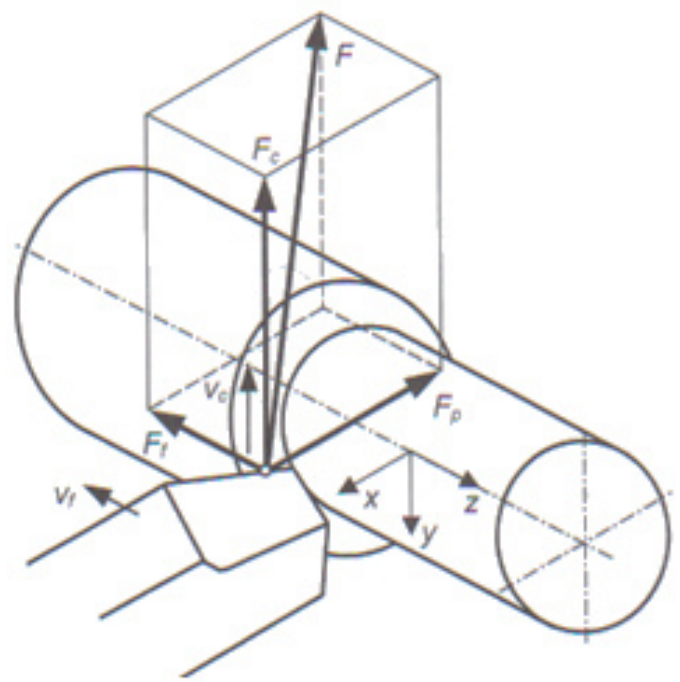

Fig. 1. Total cutting force $\mathrm{F}$ and its components for longitudinal turning: $F_{f}$ - feed force, $F_{p}$ - back force, $F_{c}$ - cutting force; $v_{c}$ - cutting speed, $v_{f}-$ feed speed

The components of the total cutting force $F$ are: $F_{c}$ - cutting force, $F_{f}$ - feed force, $F_{p}$ - back force. The cutting force $F_{c}$ load down the turning tool and causes it to bend, and also affects the mechanism of the cutting inserts fixing. In a similar way, $F_{f}$ affects the tool. In addition, this force attempts to rotate the tool around the axis of the toolholder. Its operation is not very important because it is significantly smaller than the cutting force $F_{c}$. The resistance force $F_{p}$ is on average about half the value of the force $F_{c}$.

The components of the total cutting force $\mathrm{F}$ can be calculated from various formulas usually determined on the basis of experimental investigations. They may take the form of power formulas (1):

$$
F_{c}=C_{c} \cdot v_{c}^{z} \cdot f^{y} \cdot a_{p}^{x},
$$

where: $C_{c}$ - constant in the formula, $z, y, x$ - power exponents indicating the degree of influence of the parameter on the component of the cutting force.

The formulas for the remaining components of the total cutting force are presented in a analogical way. Because the cutting speed has a very small affect on the components of the total cutting force $F$, the $v_{c}$ parameter is often omitted in the formulas. It should be noted that the more factors are included in the formulas, the more accurately the value of the $F$ force components can be determined. On the other hand, very accurate patterns are only valid for a narrow range of cutting conditions. Therefore, they cannot be transferred directly to other conditions. For this reason, a more simplified formula is often used to determine the cutting forces:

$$
F_{c}=k_{c} \cdot f \cdot a_{p}
$$

where: $k_{c}$ - specific cutting force, $\mathrm{N} / \mathrm{mm}^{2}, f$ - feed, $\mathrm{mm} / \mathrm{rev}, a_{p}-$ depth of cut, $\mathrm{mm}$.

The remaining components of the total cutting force $-F_{f}$ and $F_{p}$, with regard to turning steel and typical machining conditions, can be determined, with some approximation, from the following formulas:

$$
\begin{aligned}
& F_{f}=(0.2 \div 0.4) \cdot F_{c}, \\
& F_{p}=(0.4 \div 0.6) \cdot F_{c},
\end{aligned}
$$

The above formulas - (2), (3) and (4) have the advantage that on their basis, one can determine the force values for any machining conditions. The values of specific cutting force $k_{c}$ for typical machined materials are given in most manuals and books from the area of machining $[3,4]$.

\section{EXPERIMENTAL INVESTIGATIONS}

\subsection{Methodology of experimental investigations}

The assessments of the cutting force were carried out during external longitudinal turning of Ti-6Al-4V ELI alloy (Grade 23).

The starting point for the discussion of the Ti-6Al4V ELI alloy (Grade 23) is Ti-6Al-4V (Grade 5). It is the most commonly used titanium alloy from the group of $\alpha+\beta$ two-phase alloys [7, 13]. Introduction of aluminum to alloy the causes strengthening of the $\alpha$ phase, an increase in the thermal stability of the $\beta$ phase and a decrease in the density of the alloy $[5,6]$. The Grade 5 alloy is used mainly in aero-space and medical industries.

Ti-6Al-4V ELI alloy is the highest-purity titanium alloy, i.e. extra low interstitial (ELI). In comparison to Grade 5, it has a lower content of interstitial iron elements, hydrogen and oxygen as well as the resulting better corrosion resistance at the expense of strength. It is also worth remembering that reducing the percentage of oxygen in the alloy causes increases its plasticity and, as a result, increases the cross-section of the chip as a result of improved compression. As a result, the pressure and temperature on the tool edge decrease, 
which increases its durability [6]. The properties of the Ti-6Al-4V ELI alloy make it widely used in aerospace, aerospace and medical applications (e.g. implants).

The tests were carried out on the setup (Fig. 2), which includes: a CNC 2-axis lathe SL-10 (Haas Auto-mation, Oxnard, CA, USA) (1), a 3-component piezo-electric toolholder dynamometer type 9121 (Kistler, Winterthur, Switzerland) (2), a multichannel charge amplifier type 5070 (Kistler, Winterthur, Switzerland) (3) as well as a data acquisition card type 2855A4 with DynoWave software installed in the computer station (4).

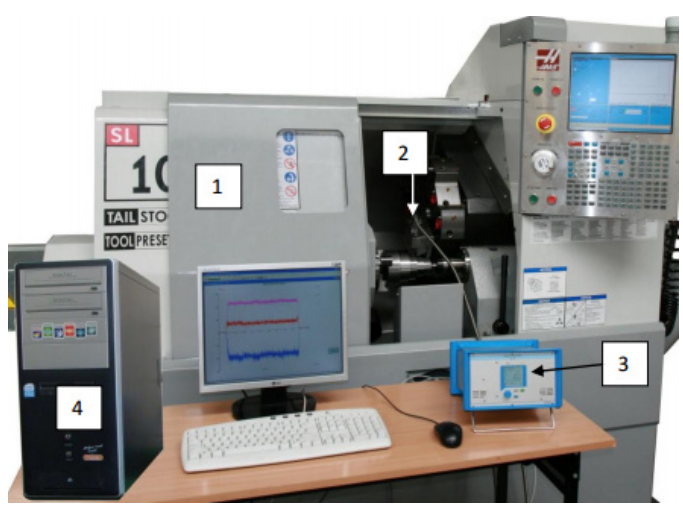

Fig. 2. General view of experimental setup for measuring the components of cutting force during turning

In the piezoelectric toolholder dynamometer type 9121, a shank tool for turning, marked according to the ISO standard - DCLNR 2020K 12 (Sandvik, Stockholm, Sweden) was used. In the tool, the cutting edge angle $\kappa r=95^{\circ}$, tool lead angle $\alpha o=-5^{\circ}$, orthogonal rake angle $\gamma o=6^{\circ}$ and inclination angle $\lambda s=-6^{\circ}$.

In the holder, the cutting inserts - CNMG 1204 08-SM (Sandvik, Stockholm, Sweden), made of sintered carbides H13A without anti-wear coating were fixed. The manufacturer recommends them mainly for roughing of heat-resistant steels and titanium alloys [12].

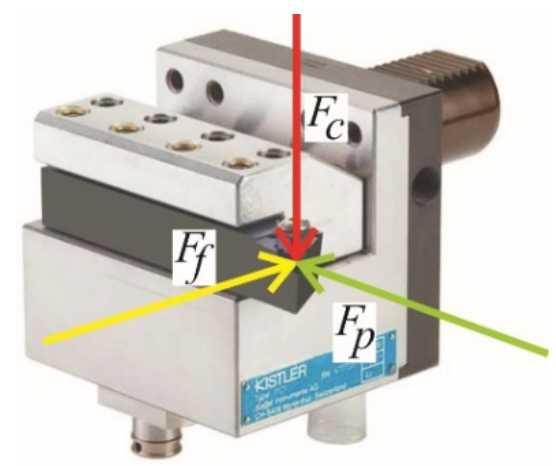

Fig. 3. 3-component piezoelectric toolholder dynamometer type 9121 (Kistler, Winterthur, Switzerland); $F_{f}$ - feed force, $F_{p}$ - back force, $F_{c}$ - cutting force [14]
The 3-component piezoelectric toolholder dynamometer type 9121 (Kistler, Winterthur, Switzerland) (Fig. 3) measures three components of the total cutting force $F: F_{f}$ - feed force, $F_{p}$ - back force and $F_{c}-$ cutting force. In order to correctly register the force $F$ components, the dynamometer was calibrated according to the card provided by the device manufacturer [15].

The investigations were carried out for the cutting parameters presented given in Table 1. The parameters were selected as recommended by Sandvik - the manufacturer of cutting inserts. During the investigations, a metalworking fluid was used. In this case, the Author chose Blasocut emulsion (Blaser Swisslube, Rüegsau, Switzerland) with the coolant flow rate $Q_{C F}=5 \mathrm{l} / \mathrm{min}$.

Tab. 1. Cutting parameters

\begin{tabular}{|c|c|c|c|}
\hline $\begin{array}{l}\text { Test } \\
\text { no. }\end{array}$ & $\begin{array}{c}\text { Cutting speed } \\
v_{c}, \mathrm{~m} / \mathrm{min}\end{array}$ & $\begin{array}{l}\text { Feed } f, \\
\mathrm{~mm} / \mathrm{rev}\end{array}$ & $\begin{array}{c}\text { Depth of cut } \\
a_{p}, \mathrm{~mm}\end{array}$ \\
\hline 1 & \multirow{3}{*}{25} & 0.10 & \multirow{9}{*}{1} \\
\hline 2 & & 0.25 & \\
\hline 3 & & 0.40 & \\
\hline 4 & \multirow{3}{*}{35} & 0.10 & \\
\hline 5 & & 0.25 & \\
\hline 6 & & 0.40 & \\
\hline 7 & \multirow{3}{*}{40} & 0.10 & \\
\hline 8 & & 0.25 & \\
\hline 9 & & 0.40 & \\
\hline
\end{tabular}

The value of the $F_{c}$ cutting force was calculated on the basis of Formula (5) taken from the SECO information materials published in [16]:

$$
F_{c}=f \cdot a_{p} \cdot k_{c} \quad[N],
$$

The value of $k_{c}$ was calculated from the formula given below (6):

$$
k_{c}=\frac{1-0.01 \cdot \gamma_{o}}{h^{m_{c}}} \cdot k_{c 1.1}\left[\frac{\mathrm{N}}{\mathrm{mm}^{2}}\right],
$$

where: $\gamma_{o}$ - orthogonal rake angle, ${ }^{\circ}, k_{c l .1}-$ specific cutting force for the selected material, $\mathrm{N} / \mathrm{mm}^{2}$ and $m_{c}-$ material factor according to SECO. The values of $k_{c 1.1}$ and $m_{c}$ were given from the tables available in the SECO catalogue. Their values for titanium-based superalloys are: $k_{c l .1}=1450 \mathrm{~N} / \mathrm{mm}^{2}$ and $m_{c}=0.23$.

The value of the nominal thickness of cut $h$ was calculated from the formula given below (7):

$$
h=f \cdot \sin \kappa_{r} \quad[m m],
$$

where: $\kappa_{r}$ - cutting edge angle, ${ }^{\circ}$.

The values of the remaining components of the total cutting force were calculated on the basis of Formulas (3) and (4). In Formula (3), the coefficient 0.3 is used, whereas in Formula (4), the coefficient value is 0.5 .

\subsection{Results and discussion}

In Figure 4 shows the graph of the course of the components of the total cutting force obtained during the measurement. The course of the cutting force $F_{c}$ is 
marked in pink, the back force $F_{p}$ in red, and the blue feed force $F_{f}$. In a character of each of the components can observe the occurrence of leap changes in the level of force value. Because the measurement was carried out by changing the cutting parameter sets in one tool pass, each of the "stairs" (Fig. 4) corresponds to the next set of cutting parameters (the next test). Such a juxtaposition of all components in one graph facilitated the comparison of the variation of the $F$ force components depending on the change of cutting parameters.

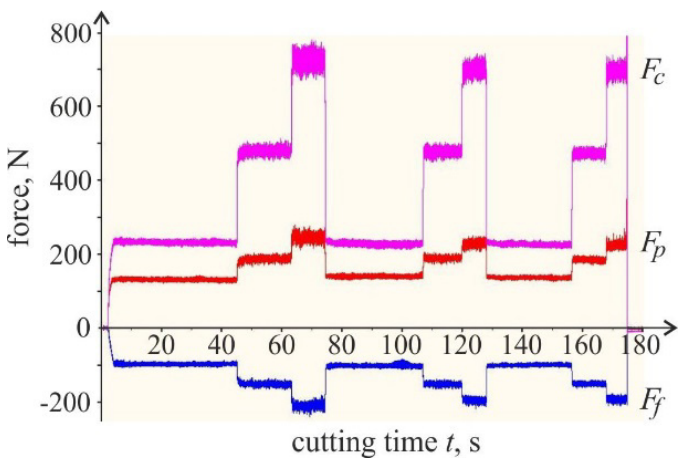

Fig. 4. Graph showing the course of the components of the total cutting force $F$

In Table 2 the results for components of the total cutting force $F$ obtained from the graph above (Fig. 4) were setting up.

Tab. 2. Force $F$ and its components - measured values

\begin{tabular}{ccccc}
\hline Test no. & $F_{p}, \mathrm{~N}$ & $F_{f}, \mathrm{~N}$ & $F_{c}, \mathrm{~N}$ & $F, \mathrm{~N}$ \\
\hline 1 & 132.2 & 96.8 & 230.1 & 284.1 \\
\hline 2 & 188.0 & 151.0 & 480.0 & 537.2 \\
\hline 3 & 245.7 & 209.6 & 724.0 & 792.8 \\
\hline 4 & 140.3 & 101.2 & 228.7 & 286.7 \\
\hline 5 & 189.0 & 151.3 & 477.4 & 535.3 \\
\hline 6 & 228.3 & 194.8 & 700.2 & 761.8 \\
\hline 7 & 137.3 & 99.4 & 227.3 & 283.6 \\
\hline 8 & 185.8 & 150.2 & 473.7 & 530.6 \\
\hline 9 & 225.6 & 192.3 & 696.0 & 756.5 \\
\hline
\end{tabular}

Based on the results presented in Table 2, can be concluded that for the tested range of cutting data, increasing the feed $f$ at constant cutting speeds $v_{c}$ occurring increases the components $F_{f}, F_{p}, F_{c}$ and total force $F$.

These differences are similar for individual speeds. The force $F$ values for $f=0.1 \mathrm{~mm} / \mathrm{rev}$ are $\sim 170 \%$ higher from the value for $f=0.4 \mathrm{~mm} / \mathrm{rev}$. However, the $F$ force values for $f=0.4 \mathrm{~mm} / \mathrm{rev}$ are $\sim 90 \%$ higher than the value of $F$ for $f=0.25 \mathrm{~mm} / \mathrm{rev}$ Changes in the cutting speed $v_{c}$ with the same feed change only the total force $F$ by about $2-4 \%$. The above observations and comments are confirmed by the graph in Figure 5 .
In this figure, the values of cutting force $F_{c}$ measured for each cutting test were presented. It is widely believed that the cutting force $F_{c}$ is the most representative component in the analysis of machining processes. As is apparent from the literature, the remaining components are less important at the analyses of tool loading by cutting forces. This is mainly due to the highest value of $F c$ cutting force among all components and the fact that it loads the tool, mainly causing its bending and affects the mechanisms that fix the cutting insert [10].

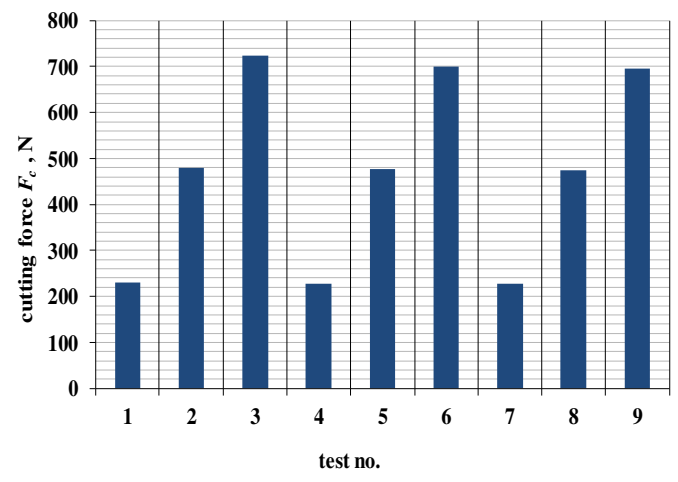

Fig. 5. Graph showing the values of cutting force $F_{c}$ measured for each cutting test

In Table 3 the values for components of the total cutting force $F$ calculated on the basis of the universal formulas given in Section 3 were setting up.

Tab. 3. Force $F$ and its components - calculated values

\begin{tabular}{ccccc}
\hline Test no. & $F_{p}, \mathrm{~N}$ & $F_{f}, \mathrm{~N}$ & $F_{c}, \mathrm{~N}$ & $F, \mathrm{~N}$ \\
\hline 1 & 115.8 & 69.5 & 231.6 & 268.1 \\
\hline 2 & 234.5 & 140.7 & 469.0 & 542.9 \\
\hline 3 & 336.8 & 202.1 & 673.6 & 779.8 \\
\hline 4 & 115.8 & 69.5 & 231.6 & 268.1 \\
\hline 5 & 234.5 & 140.7 & 469.0 & 542.9 \\
\hline 6 & 336.8 & 202.1 & 673.6 & 779.8 \\
\hline 7 & 115.8 & 69.5 & 231.6 & 268.1 \\
\hline 8 & 234.5 & 140.7 & 469.0 & 542.9 \\
\hline 9 & 336.8 & 202.1 & 673.6 & 779.8 \\
\hline
\end{tabular}

Due to the fact that only the $F_{c}$ component is calculated from the formula, which takes into account the machining conditions, to compare the values of forces measured and calculated to the cutting force $F_{c}$ was used. The graph in Figure 6 shows the measured and calculated values of the cutting force $F_{c}$.

When comparing the results in Tables 2 and 3 as well as in Figure 6, we see that for feed $f=0.25 \mathrm{~mm} /$ rev (Test 2, 5 and 8) and $f=0.4 \mathrm{~mm} / \mathrm{rev}$ (Test 3, 6 and 9) the calculated cutting force $F_{c}$ has a lower value 
than the corresponding measured force. For the feed $f$ $=0.1 \mathrm{~mm} / \mathrm{rev}$ (Test 1, 4 and 7), the opposite situation occurs, i.e. the measured force is lower than the calculated one. For feed $f=0.1 \mathrm{~mm} / \mathrm{rev}$, the difference between the calculated force and the mea-sured force is negligibly small and amounts to $\sim 1 \%$. For feed $f=$ $0.25 \mathrm{~mm} / \mathrm{rev}$, the difference is about $2 \%$, and for feed $f$ $=0.4 \mathrm{~mm} / \mathrm{rev}$ takes values between 3 and $7 \%$.

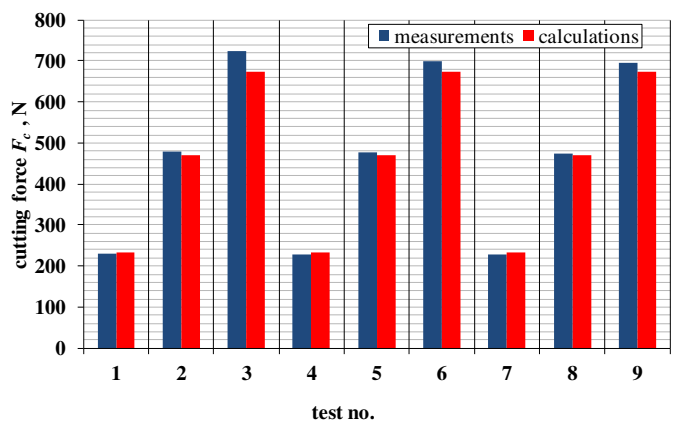

Fig. 6. Graph showing the measured and calculated values of cutting force $F_{c}$ for each cutting test

\section{CONCLUSIONS}

Based on the conducted investigations, it can be concluded that for the tests conditions used.

1. The $v_{c}$ cutting speed has a negligible influence on changes in the total cutting force $F$ and its components.

2. Feed $f$ significantly influences the change in cutting forces. Its increase, in the tested range, resulted in an increase of cutting forces by up to $170 \%$.

3. The values of forces calculated on the basis of simplified formulas are similar to the values measured experimentally. Small differences between them result mainly from the lack of provision of all the machining conditions in the formulas.

4. Simplified formulas available in the literature can be used to determine the values of the total cutting force $F$.

\section{Acknowledgements}

The Author wishes to thank Wojciech Kapłonek, $\mathrm{PhD}$, DSc, ME (Faculty of Mechanical Engineering, Koszalin University of Technology) for his help in the language correction of this paper.

\section{Nomenclature}

\section{Symbols}

$a_{p} \quad-$ depth of cut, mm

$C_{c} \quad-$ constant in the formula for $F_{c}$ calculation

$f \quad-$ feed, $\mathrm{mm} / \mathrm{rev}$

$F \quad-$ total cutting force, $\mathrm{N}$

$F_{c} \quad$ - cutting force, $\mathrm{N}$

$F_{f} \quad-$ feed force, N

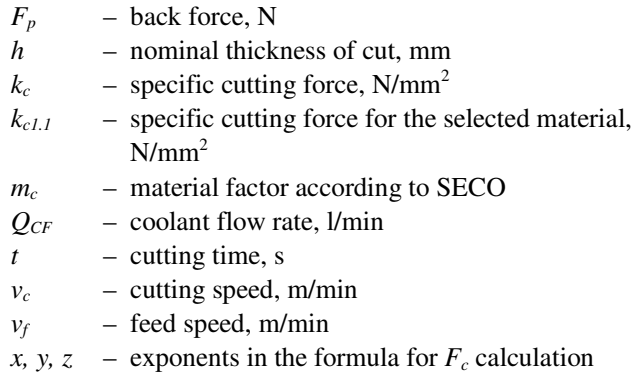

\section{Greek letters}

$\alpha_{o} \quad-$ tool lead angle, ${ }^{\circ}$

$\gamma_{o} \quad-$ orthogonal rake angle, $^{\circ}$

$\kappa_{r} \quad-$ (tool major) cutting edge angle, ${ }^{\circ}$

$\lambda_{s} \quad-$ inclination angle, ${ }^{\circ}$

\section{Acronyms}

BUE - built-up edge

CNC - computerized numerical control

ELI - extra low interstitial

\section{References}

1. Ezugwu E.O., Bonney J., Yamane Y. (2003). An overview of the machinability of aeroengine alloys. Journal of Materials Processing Technology, Vol. 134, No. 2, pp. 233-253.

2. Ezugwu E.O., Wang Z.M.Y. (1997). Titanium alloys and their machinability - a review. Journal of Materials Processing Technology, Vol. 68, No. 13, pp. 262-274.

3. Kowalczyk M. (2012). Then chip compression ratio analysis in the aspect of Ti-6Al-4V alloy turning with eleveted cutting speeds. Technical Transactions, Vol. 109, No. 22, pp. 55-69. (in Polish)

4. Narojczyk J., Moroz D., Siemiątkowski Z. (2015). Machining titanium alloy Ti-6Al-4V implanted carbide tools. Mechanik, No. 3, pp. 359-362. (in Polish)

5. Walczak M., Waśkowicz M., Bieniaś J. (2003). Profile microstructural of chosen materials titanic practical in prosthetics the dentists. Eksploatacja i Niezawodnosc Maintenance and Reliability, No. 2, pp. 70-74. (in Polish)

6. Bylica A., Sieniawski J. (1987). Titanium and ist alloys. PWN, Warszawa. (in Polish)

7. Grzesik W. (2008). Advanced machining processes of metallic materials. Theory, modelling and applications. Elsevier.

8. Jastrzębski T. (1999). Titanium alloys in ocean engineering constructions. Zeszyty Naukowe - Mechanika, (Politechnika Opolska), Vol. 58, pp. 43-54. (in Polish)

9. Kadłuczka A., Mazur M. (2009). Corrosion of two phase $\mathrm{Ti}$ alloy in $\mathrm{HCl}$ environment. Technical Transactions, Vol. 106, No. 6, pp 59-66. (in Polish)

10. Kowalczyk M. (2013). Measurements of cutting forces and surface roughness when precision turning of pure titanium. Journal of Machine Engineering, Vol. 18, No. 4, pp. 55-71. (in Polish)

11. Ezugwu E.O., Bonney J., Da Silva R.B., Cakir O. (2007). Surface integrity of finished turned Ti-6Al-4V alloy with PCD tools using conventional and high pressure coolant supplies. International Journal of Machine Tools and Manufacture, Vol. 47, No. 6, pp. 884-891.

12. www.sandvik.pl (20.19.2018)

13. Arrazola P.-J., Garay A., Iriarte L.-M., Armendia M., Marya S., Maître Le F.(2009). Machinability of titanium alloys (Ti6Al4V and Ti555.3). Journal of Materials Processing Technology, Vol. 209, No. 5, pp. 2223-2230. 
14. Stachurski W., Midera S., Kruszyński B. (2012). Determination of mathematical formulae for the cutting force $F_{c}$ during the turning of $\mathrm{C} 45$ steel. Mechanics and Mechanical Engineering, Vol. 16, No. 2, pp. 73-79.

15. www.kistler.com (20.10.2018)

16. www.secotools.com $(20.10 .2018)$

\section{Biographical notes}

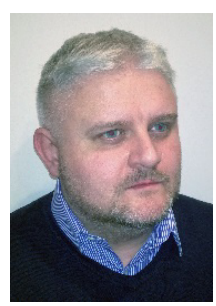

Wojciech Stachurski received his M.Sc. degree in Production Engineering and Ph.D. degree in Machinery Construction and Operation from the Lodz University of Technology, in 2001 and 2008, respectively. Since 2003, he has been a researcher in the Institute of Machine Tools and Production Engineering at the Lodz University of Technology, where currently he works as an assistant professor. His scientific interests focus on abrasive processes, technological research of the surface texture as well as wear and durability of cutting tools. He has participated in 3 national research projects as well as 5 international and 14 national conferences. He has published more than 60 scientific papers in various international and national journals. He is also the author of 2 national patents. 